\title{
A pilot study on metabolic syndrome and its associated features among Qatari schoolchildren
}

This article was published in the following Dove Press journal:

International Journal of General Medicine

I I July 201 I

Number of times this article has been viewed

Nasser Rizk

Mona Amin

Mervat Yousef

Health Sciences Department, University of Qatar, Doha, Qatar
Correspondence: Nasser Rizk Health Sciences Department, CAS-Qatar University, 27I3-Doha, Qatar

Tel +97444034786

Fax +974 4403480 I

Email nassrizk@qu.edu.qa
Aim: This pilot study aimed to evaluate the individual features of the metabolic syndrome (MeS) and its frequency in Qatari schoolchildren aged 6-12 years.

Background: MeS has a strong future risk for development of diabetes and cardiovascular diseases. Childhood obesity is increasing the likelihood of MeS in children.

Methods: The associated features of MeS were assessed in 67 children. They were recruited from the outpatient pediatric clinic at Hamad Medical Corporation, Qatar. Height, weight, and waist circumference were measured and body mass index was calculated for each child. Fasting blood glucose, total cholesterol, high-density lipoprotein cholesterol (HDL-C), low-density lipoprotein cholesterol and triglycerides (TG) were measured. MeS was defined according to the National Cholesterol Education Program Adult Treatment Panel III (NCEP-III) which was modified by Cook with adjustment for fasting glucose to $\geq 5.6 \mathrm{mM}$ according to recommendations from the American Diabetes Association.

Results: The overall prevalence of MeS according to NCEP-III criteria was $3.0 \%$ in children aged 6-12 years. Overweight and obesity was $31.3 \%$ in children aged 6-12 years, according to the International Obesity Task Force criteria. The prevalence of MeS was $9.5 \%$ in overweight and obese subjects. Increased TG levels represented the most frequent abnormality $(28.4 \%)$ in metabolic syndrome features in all subjects, followed by HDL-C $(19.4 \%)$ in all subjects.

Conclusion: Increased TG levels and low HDL-C were the most frequent components of this syndrome. This study showed a significant prevalence of $\mathrm{MeS}$ and associated features among overweight and obese children. The overall prevalence of MeS in Qatari children is in accordance with data from several other countries.

Keywords: metabolic syndrome, National Cholesterol Education Program Adult Treatment Panel III, schoolchildren, Qatar

\section{Introduction}

Several studies have demonstrated that cardiovascular diseases (CVD) begin early in childhood and atherosclerotic changes may occur early in the life of children with lipid abnormalities. ${ }^{1,2}$ Metabolic syndrome (MeS) clusters consist of obesity, insulin resistance, hypertension, impaired glucose tolerance, hyperinsulinemia and dyslipidemia associated with low high density lipoprotein cholesterol (HDL-C) and hypertriglyceridemia. ${ }^{3}$

Childhood obesity is increasing worldwide including in Qatar, ${ }^{4,5}$ thus increasing the likelihood of MeS in children. ${ }^{6}$ Physicians need to screen and detect early manifestations of MeS clusters during childhood, particularly among obese children. 
The State of Qatar is a small country in the Arab Gulf area. Data relevant to $\mathrm{MeS}$ are limited among Qatari schoolchildren, therefore this study aimed to investigate the frequency of MeS and its associated features in 6 to 12 year old Qatari children.

\section{Methods}

This cross-sectional study involved a total of 67 subjects aged 6-12 years (30 males and 37 females). A convenient sample was recruited from the pediatric outpatient clinic at Hamad Medical Corporation (HMC), Qatar, from March 2005 to August 2005. The study was approved by the Research Ethics committee of HMC and informed consent was obtained.

Body weight was measured, using a Seca 634 digital electronic platform scale (Birmingham, UK) with precision to $0.1 \mathrm{~kg}$, following a standardized procedure (lightly dressed, without shoes). Standing height was measured to the nearest $0.1 \mathrm{~cm}$ with the use of a stadiometer. Body mass index (BMI) was calculated by dividing weight in $\mathrm{kg}$ by height squared in meters. Waist circumference (WC) was measured in duplicate by means of a nonelastic flexible tape, with subjects standing, at the smallest abdominal position between the iliac crest and the lower rib margin at the end of normal expiration. The measurements were recorded to the nearest $0.5 \mathrm{~cm}$. Blood pressure (BP) was measured in triplicate on the arm with the patient seated after rest, using a digital sphygmomanometer and appropriate sized cuff. A fasting blood sample was drawn. Blood glucose, total cholesterol (TC), triglycerides (TG), high density lipoprotein cholesterol (HDL-C) and low density lipoprotein cholesterol (LDL-C) were determined as previously published. ${ }^{7}$

$\mathrm{MeS}$ was defined according to the National Cholesterol Education Program Adult Treatment Panel III (NCEP-III) ${ }^{8}$ which was modified by Cook, ${ }^{9}$ with adjustment for fasting glucose to $\geq 5.6 \mathrm{mM}$ according to American Diabetes Association recommendations. ${ }^{10} \mathrm{MeS}$ required the presence of 3 components out of 5 of the following criteria:

1. Abdominal obesity with waist circumference $\geq 90$ th percentile for age/gender, according to previous studies. ${ }^{9,11} \mathrm{~A}$ recent study evaluating the waist circumference reference values for screening cardiovascular risk factors in Chinese children and adolescents aged 7-18 years, indicated a slight increasing trend of cardiovascular risk factors starting from the 75th percentile of waist circumference in the study population, while a significant increasing trend occurred from the 90 th percentile. ${ }^{12}$
2. Impaired fasting glucose (glucose $\geq 5.6 \mathrm{mM}$ ).

3. Systolic/diastolic blood pressure ( $\geq 90$ th percentile for height, age, and gender).

4. $\mathrm{TG} \geq 1.24 \mathrm{mM}$.

5. HDL-C $\leq 1.036 \mathrm{mM}$ or below the 5th percentile.

The International Obesity Task Force (IOTF) criterion was adopted for classification of children as overweight and obese. $^{13}$

\section{Statistical analysis}

Statistical evaluation was performed with SPSS, PC (program for Windows, version 19, SPSS Inc, Chicago, IL). Student's $t$-test was used for comparison between groups. Comparisons of frequencies of individual components and the numbers of $\mathrm{MeS}$ were performed using the Chi-Square test. A level of $P<0.05$ was considered statistically significant.

\section{Results}

The anthropometric, clinical, and biochemical characteristics of the 67 children are presented by gender in Table 1. Boys had a statistically significant higher value for TG than girls. Using IOTF, 10 boys (14.9\%) and 11 girls (16.4\%) were overweight and obese.

Table 2 and Figure 1 present the individual components of $\mathrm{MeS}$ by gender and overweight and obesity status. Hypertriglyceridemia was the most frequent component of MeS (28.4\%) among all subjects, and was significantly higher among boys than girls. The second order of frequency among MeS components was low HDL-C (19.4\%), followed by hyperglycemia $(16.4 \%)$, then hypertension $(10.5 \%)$ and lastly by abdominal obesity (4.5\%). The overall incidence of MeS among all children was $3.0 \%$. The two subjects presenting with MeS were obese. The number of components of MeS was higher in boys than girls, $(33.3 \%$ versus $29.7 \%),(30.0 \%$ versus $13.5 \%)$ and $(3.3 \%$ versus $2.7 \%)$ for one, two and three components respectively. The number of components of $\mathrm{MeS}$ was significantly higher in overweight and obese children than non-overweight and non-obese children, (42.9\% versus $17.4 \%)$, (38.1\% versus $13.0 \%)$ and $(9.5 \%$ versus $0.0 \%)$ for one, two and three components respectively (Figure 2).

\section{Discussion}

The current study revealed that $3.0 \%$ of all study subjects had MeS according to NCEP-III criteria, ${ }^{8}$ modified by Cook's criteria $^{9}$ with adjustment for fasting glucose to $\geq 5.6 \mathrm{mM}$ 
Table I Descriptive characteristics of a sample of Qatari school children 6 to 12 years-old by gender

\begin{tabular}{|c|c|c|c|c|}
\hline & All & Boys $(n=30)$ & Girls $(n=37)$ & $\mathbf{P}$ \\
\hline Age (Years) & $8.34(7.8 \mathrm{I}-8.88)$ & $8.40(7.55-9.25)$ & $8.30(7.59-9.01)$ & 0.849 \\
\hline Weight (kg) & $31.05(28.14-33.95)$ & $31.96(27.77-36.16)$ & $30.30(26.11-34.49)$ & 0.387 \\
\hline Height (cm) & 131.10 (1.28-1.35) & $132.90(\mid 28.0-137.8)$ & $129.70(\mid 25.0-134.5)$ & 0.148 \\
\hline BMI $\left(\mathrm{kg} / \mathrm{m}^{2}\right)$ & $17.4 \mid(|6.52-| 8.3 \mid)$ & 17.56 (16.29-18.86) & 17.28 (I5.98-|8.57) & 0.734 \\
\hline ow/ob, n (\%) & $21.00(31.3 \%)$ & $10.00(14.9 \%)$ & II.00 (I6.4\%) & 0.752 \\
\hline WC $(\mathrm{cm})$ & $57.42(54.79-60.05)$ & $58.82(54.36-63.27)$ & $56.28(53.03-59.54)$ & 0.200 \\
\hline $\mathrm{SBP}(\mathrm{mm} \mathrm{Hg})$ & $100.08(97.33-102.82)$ & $102.07(97.56-106.58)$ & 98.46 (94.66-101.93) & 0.120 \\
\hline DBP (mm Hg) & 54.57 (52.19-56.94) & $54.20(50.57-57.83)$ & $54.87(51.57-58.16)$ & 0.766 \\
\hline Glucose (mM) & $4.92(4.72-5.11)$ & $4.98(4.69-5.27)$ & $4.87(4.59-5.14)$ & 0.847 \\
\hline $\mathrm{TC}(\mathrm{mM})$ & $4.38(4.18-4.58)$ & $4.29(3.92-4.65)$ & $4.46(4.24-4.67)$ & 0.655 \\
\hline TG (mM) & I.II (0.95-I.27) & $1.29(0.99-1.58)$ & $0.97(0.80-1.13)$ & $0.044 *$ \\
\hline HDL-C (mM) & $1.59(1.45-1.72)$ & $1.50(1.32-1.68)$ & $1.66(1.46-1.86)$ & 0.578 \\
\hline LDL-C (mM) & $2.20(2.02-2.39)$ & $2.18(1.83-2.54)$ & $2.2(2.02-2.42)$ & 0.722 \\
\hline
\end{tabular}

Notes: Numerical data are presented as mean values (95.0\% lower-upper confidence interval), and Student's t-test was used for the difference of continuous variables between genders adjusted for age and gender. Categorical data are presented by number and \%, and a Chi-square test was used to evaluate the difference between genders. $P$ value is significant at $\leq 0.05$.

Abbreviations: BMI, body mass index; WC, waist circumference; MeS, metabolic syndrome; ow and ob, overweight and obese; TC, total cholesterol; HDL-C, high-density lipoprotein cholesterol; LDL-C, low-density lipoprotein cholesterol; TG, triglycerides; SBP, systolic blood pressure; DBP, diastolic blood pressure.

according to American Diabetes Association recommendations. ${ }^{10}$ Though direct comparison across studies is difficult since the definitions of the syndrome are different, the results of the current study are in agreement with a previous study by Cruz and Goran, which demonstrated that the overall prevalence of $\mathrm{MeS}$ in children was $3.0 \%$ to $4.0 \%$ in the USA. ${ }^{14}$ The current results are similar to data among Turkish schoolchildren aged $10-19$ years $(2.3 \%)$ according to International Diabetes Foundation (IDF) and NECP-III criteria. ${ }^{15}$ Using a definition comparable to that projected in NECP-III criteria, a prevalence of 3.6\% in children 8-17 years of age was reported by investigators from the Bogalusa Heart Study. ${ }^{16}$ Using the IDF definition, the prevalence of $\mathrm{MeS}$ in Jordanian children $10-15$ years old was (1.4\%). ${ }^{17}$ The prevalence of MeS in Caucasian children was reported to be $6.0 \%$ to $39.0 \%,{ }^{18}$ while it was $6.7 \%$ in Korean children and adolescents. ${ }^{19}$

Childhood obesity is increasing the likelihood of MeS in children. ${ }^{5}$ Our results report a high prevalence of MeS
(9.5\%) and its components among overweight and obese children (Figure 2). This finding is similar to other studies which demonstrated much higher prevalence rates of MeS in children who were overweight or obese. , $^{8-22}$

The reliability of diagnostic criteria for MeS in children has been questioned. It has been found that they require modification to be applicable to children. ${ }^{23}$ This may account in part for the discrepancies in prevalence between different populations. However, this study, like a number of others, identified the prevalence of various abnormalities (all included within the criteria) separately. In the whole sample studied, the most frequently found abnormality (Figure 1) was hypertriglyceridemia (28.4\%) followed by low HDL (19.4\%). These findings support those of other studies indicating that the most common abnormality is high triglycerides and low HDL cholesterol in US children. ${ }^{8}$

This study has strengths and limitations. An important strength is that it provides additional data on Qatari

Table 2 Frequency of individual MeS components in all subjects and by gender

\begin{tabular}{|c|c|c|c|c|}
\hline $\begin{array}{l}\text { Prevalence of } \\
\text { individual MeS components }\end{array}$ & All $(n=67)$ & Boys $(n=30)$ & Girls $(n=37)$ & $P$ \\
\hline MeS, n (\%) & $2(3.0)$ & I (3.3) & I (2.7) & - \\
\hline High WC & $3(4.5 \%)$ & $3(10.0 \%)$ & $0(0.0 \%)$ & 0.046 \\
\hline Hyperglycemia & $11(16.4 \%)$ & $5(16.7 \%)$ & $6(16.2 \%)$ & 0.961 \\
\hline Low HDL-C & $13(19.4 \%)$ & $6(20.0 \%)$ & 7 (I8.2\%) & 0.911 \\
\hline High TG & $19(28.4 \%)$ & $10(33.3 \%)$ & 5 (I3.5\%) & 0.048 \\
\hline High blood pressure & $7(10.5 \%)$ & $4(13.3 \%)$ & $3(8.1 \%)$ & 0.120 \\
\hline
\end{tabular}

Notes: Categorical data are presented by number (\%). A Chi-square test was used to evaluate the difference between genders. $P$ value is significant at $\leq 0.05$.

Abbreviations: WC, waist circumference; MeS, metabolic syndrome; HDL-C, high-density lipoprotein cholesterol; TG, triglycerides. 


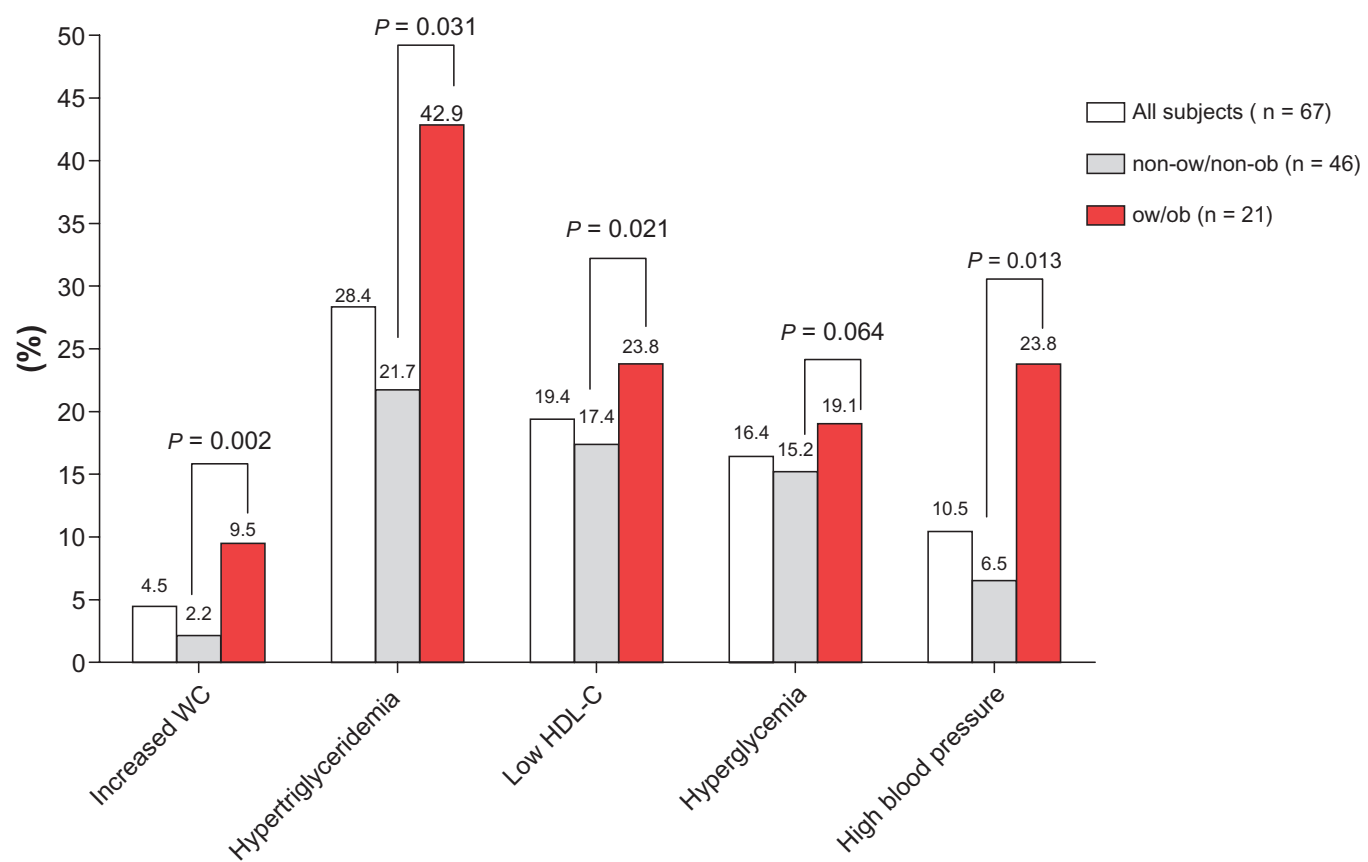

Figure I Frequency of individual MeS components (\%) in all subjects and according to overweight/obesity status.

Notes: The $P$ value indicates the difference in frequency distribution of individual MeS components between non-ow \& non-ob and ow/ob children. A level of $P<0.05$ is statistically significant.

Abbreviations: WC, waist circumference; MeS, metabolic syndrome; ow and ob, overweight and obese; non-ow and non-ob, non-overweight and non-obese; HDL-C, high-density lipoprotein cholesterol.

schoolchildren relating to $\mathrm{MeS}$, which was previously lacking. The major limitations are the small sample size and an ongoing debate on the accuracy of diagnosing the MeS in children younger than 10 years old.

In conclusion, our results indicate that though the prevalence of $\mathrm{MeS}$ is low overall in Qatari children, overweight and obese children had higher rates of MeS than non-over weight and non-obese children. A large proportion of Qatari schoolchildren had one or two metabolic abnormalities. Further studies are needed, with larger sample sizes, including measurements of hormones and biomarkers known to be involved in pathogenesis and identification of MeS in Qatari school children.

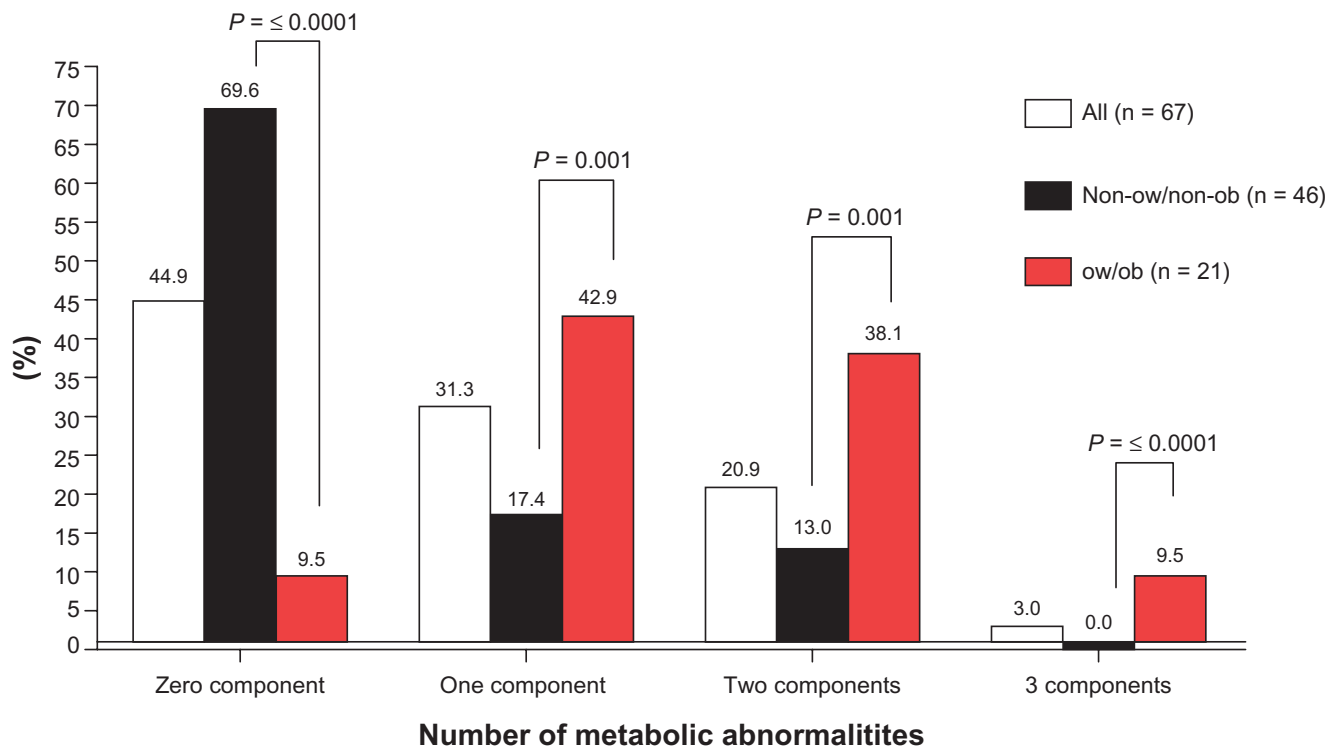

Figure 2 The frequency of clustering of metabolic abnormalities among Qatari school children aged between 6 and 12 years according to overweight/obesity status. Notes: The $P$ value indicates the difference in frequency of clustering of MeS components between non-ow and non-ob and ow/ob children. A level of $P<0.05$ is statistically significant. Abbreviations: ow and ob, overweight and obese; non-ow and non-ob, non-overweight and non-obese. 


\section{Abbreviations}

BMI, body mass index; WC, waist circumference; MeS, metabolic syndrome; IOTF, International Obesity Task Force; ow and ob, overweight and obese; non-ow and non-ob, nonoverweight and non-obese; TC, total cholesterol; HDL-C, high-density lipoprotein cholesterol; LDL-C, low-density lipoprotein cholesterol; TG, triglycerides; CVD, cardiovascular diseases.

\section{Acknowledgment}

This work was supported by grant \#CAS05001 from Qatar University, Qatar.

\section{Disclosure}

The authors report no conflicts of interest in this work.

\section{References}

1. Kavey RE, Daniels SR, Lauer RM, Atkins DL, Hayman LL, Taubert K. American Heart Association guidelines for primary prevention of atherosclerotic cardiovascular disease beginning in childhood. J Pediatr. 2003;142(4):368-372.

2. Juonala M, Viikari JS, Ronnemaa T, et al. Associations of dyslipidemias from childhood to adulthood with carotid intima-media thickness, elasticity, and brachial flow-mediated dilatation in adulthood: the Cardiovascular Risk in Young Finns Study. Arterioscler Thromb Vasc Biol. 2008;28(5):1012-1017.

3. Reaven GM. Banting lecture 1988. Role of insulin resistance in human disease. Diabetes. 1988;37(12):1595-1607.

4. Wang Y, Lobstein T. Worldwide trends in childhood overweight and obesity. Int J Pediatr Obes. 2006;1(1):11-25.

5. Bener A, Kamal AA. Growth patterns of Qatari school children and adolescents aged 6-18 years. J Health Popul Nutr. 2005;23(3):250-258.

6. Crespo PS, Prieto Perera JA, Lodeiro FA, Azuara LA. Metabolic syndrome in childhood. Public Health Nutr. 2007;10(10A):1121-1125.

7. El-Menyar A, Rizk N, Al Nabti AD, et al. Total and high molecular weight adiponectin in patients with coronary artery disease. J Cardiovasc Med (Hagerstown). 2009;10(4):310-315.

8. Executive Summary of The Third Report of The National Cholesterol Education Program (NCEP) Expert Panel on detection, evaluation, and treatment of high blood cholesterol in adults (Adult Treatment Panel III). JAMA. 2001;285(19):2486-2497.
9. Cook S, Weitzman M, Auinger P, Nguyen M, Dietz WH. Prevalence of a metabolic syndrome phenotype in adolescents: findings from the third National Health and Nutrition Examination Survey, 1988-1994. Arch Pediatr Adolesc Med. 2003;157(8):821-827.

10. Genuth S, Alberti KG, Bennett P, et al. Follow-up report on the diagnosis of diabetes mellitus. Diabetes Care. 2003;26(11):3160-3167.

11. Seki M, Matsuo T, Carrilho AJ. Prevalence of metabolic syndrome and associated risk factors in Brazilian schoolchildren. Public Health Nutr. 2009;12(7):947-952.

12. Ma GS, Ji CY, Ma J, et al. Waist circumference reference values for screening cardiovascular risk factors in Chinese children and adolescents. Biomed Environ Sci. 2010;23(1):21-31.

13. Cole TJ, Bellizzi MC, Flegal KM, Dietz WH. Establishing a standard definition for child overweight and obesity worldwide: international survey. BMJ. 2000;320(7244):1240-1243.

14. Cruz ML, Goran MI. The metabolic syndrome in children and adolescents. Curr Diab Rep. 2004;4(1):53-62.

15. Cizmecioglu FM, Etiler N, Hamzaoglu O, Hatun S. Prevalence of metabolic syndrome in schoolchildren and adolescents in Turkey: a population-based study. J Pediatr Endocrinol Metab. 2009;22(8): $703-714$.

16. Srinivasan SR, Myers L, Berenson GS. Predictability of childhood adiposity and insulin for developing insulin resistance syndrome (syndrome X) in young adulthood: the Bogalusa Heart Study. Diabetes. 2002;51(1):204-209.

17. Khader Y, Batieha A, Jaddou H, El-Khateeb M, Ajlouni K. Metabolic Syndrome and its individual components among Jordanian children and adolescents. Int J Pediatr Endocrinol. 2010;2010:316170. [Epub 2010 Dec 9].

18. Reinehr T, de Sousa G, Toschke AM, Andler W. Comparison of metabolic syndrome prevalence using eight different definitions: a critical approach. Arch Dis Child. 2007;92(12):1067-1072.

19. Lee YJ, Shin YH, Kim JK, Shim JY, Kang DR, Lee HR. Metabolic syndrome and its association with white blood cell count in children and adolescents in Korea: the 2005 Korean National Health and Nutrition Examination Survey. Nutr Metab Cardiovasc Dis. 2010;20(3): 165-172.

20. Weiss R, Dziura J, Burgert TS, et al. Obesity and the metabolic syndrome in children and adolescents. N Engl J Med. 2004;350(23): 2362-2374.

21. Dhuper S, Cohen HW, Daniel J, Gumidyala P, Agarwalla V, St Victor R. Utility of the modified ATP III defined metabolic syndrome and severe obesity as predictors of insulin resistance in overweight children and adolescents: a cross-sectional study. Cardiovasc Diabetol. 2007;6:4.

22. Agirbasli M, Cakir S, Ozme S, Ciliv G. Metabolic syndrome in Turkish children and adolescents. Metabolism. 2006;55(8):1002-1006.

23. Pergher RN, Melo ME, Halpern A, Mancini MC. Is a diagnosis of metabolic syndrome applicable to children? J Pediatr (Rio J). 2010;86(2): $101-108$.
International Journal of General Medicine

\section{Publish your work in this journal}

The International Journal of General Medicine is an international peer-reviewed open-access journal that focuses on general and internal medicine, pathogenesis, epidemiology, diagnosis, monitoring and treatment protocols. The journal is characterized by the rapid reporting of reviews, original research and clinical studies across all disease areas.

\section{Dovepress}

A key focus is the elucidation of disease processes and management protocols resulting in improved outcomes for the patient. The manuscript management system is completely online and includes a very quick and fair peer-review system. Visit http://www.dovepress.com/ testimonials.php to read real quotes from published authors. 